\title{
Past as Prologue: How History Becomes Psychologically Present
}

\author{
Andrea G. Hunter* \\ University of North Carolina at Greensboro
}

\author{
Abigail J. Stewart \\ University of Michigan
}

Social issues, especially when they implicate histories of injustices, often stay with us not only because they pose moral questions but also because of their consequences for individual psychologies and the relations between groups within societies. This special issue of the Journal of Social Issues focuses on different ways that social history and psychology-always coconstructing each other-matter. Focused on major events and social movements of the 20th century, we highlight work that psychologists have done that allows us, as a field, to take seriously the relationships between sociallevel events and individuals' identities and self-representations, emotional lives and well-being, approaches to social justice and collective action, motivations, and accomplishments. The individual and collective pursuit of social justice is one arena that makes links between history and psychology visible along with their implications for relations within and between social groups.

Susan Crane (1997), in her essay on collective memory writes "perhaps the most banal thing we can say about history, in general, is that 'it happened' or something happened." (p.1372). Individuals, groups, and publics grapple not only with the consequences of history but also what to make of its meaning(s) in the present and for those who will come after. To explore the intersections of psychology and history requires that we make history present as more than just a context, an event, or location. Social issues, especially those for which histories of injustices are implicated, often stay with us as publics not only because they pose

\footnotetext{
${ }^{*}$ Correspondence concerning this article should be addressed to Andrea G. Hunter, Department of Human Development and Family Studies, P.O. Box 26107, The University of North Carolina at Greensboro, Greensboro, NC, 27402 [e-mail: aghunter@uncg.edu].
} 
moral questions but also because of their consequences for individual psychologies and the relations between groups within societies. And more, individually and collectively, we are charged with what and how we will remember or forget what is past. In a New Yorker essay, Phillip Gourevtich (2014, p. 3) described the wrenching emotion that accompanied the genocide-commemoration during the national week of mourning in Rwanda and observed that "there is memory that we manage, and memory that manages us" and so it can be said of history. This special issue of the Journal of Social Issues focuses on different ways that social history and psychology—always co-constructing each other-matter. We highlight work that psychologists have done that allows us, as a field, to take seriously the impact that social-level events have not so much for individual behavior but for individuals' identities and self-representations, emotional lives and well-being, approaches to social justice and collective action, motivations and accomplishments. The individual and collective pursuit of social justice is one arena that makes links between history and psychology visible, along with their implications for relations within and between social groups. We hope also to offer insight into the processes by which social history and psychology are linked, and the role of publics in what and how we remember or forget.

\section{The Social Past and 20th Century Transformations}

Participants in the studies included in this issue grapple with making personal meaning of major events and social movements of the 20th century. As we continue to confront the social, political, economic, and cultural transformations the 20th century brought, researchers in this issue ask in diverse ways, what were "its meanings for inner life of a variety of individuals" (Mills, p. 8). Global war and peace, social movements, the rise and fall of independent states and nations, economic collapse and prosperity, and state sponsored and spontaneous acts of repression and genocide have variously led to transformations in individual lives, in group relations, the boundaries of nation states, and in the social positions of excluded groups. In this issue, we focus primarily on events from the mid-20th century forward including World War II, the Holocaust, and Japanese internment; early 20th century race riots and the Civil Rights Movement; waves of feminism and the Women's Movement; the fall of the Soviet Union; civil wars in Central America; and the Palestinian/Israeli conflict. Though it is not possible in one issue to address the full scope of historical events or social movements that have in some significant way defined the latter half of 20th century (for example, postwar rebuilding of Europe and Japan, and postcolonial nation-building in Africa, Asia, and Latin America are not represented), we do include historical moments that illustrate the last century's quests for identity, contestations of nation and peoplehood, and struggles for social justice that continue to resonate today in individuals, social groups, communities, and nations. 


\section{How are History and Psychology Linked?}

We assume that history and psychology are always mutually constitutive. The experience of individuals and groups is always saturated with historical significance, whether recognized or not. Equally, psychology is always operating in history through the actions and reactions of individuals and groups. In this volume we consider history not only in terms of events and experiences that happened at a particular moment in time but also in terms of personal history that intersects with historical events or movements, as collective histories of social groups that are variously shaped by history writ large, as well as what people individually and collectively interpret as history. We have brought together psychologists from different subfields, with different approaches to understanding the importance of the past for psychology, but across their different approaches a number of core processes have been demonstrated to matter, within different domains in psychology. These processes include emotions, memory, identity, social representation, and ideas about social justice.

Emotions. Autobiographical memory researchers have demonstrated that emotions felt at the time of an experience-particularly intense emotionsincrease the likelihood that the experience will be encoded in memory, eventually sometimes to be integrated into a personal identity (Brown \& Kulik, 1977; Pillemer, 1984, 1998, 2001; Rubin, 1986). Feelings of intense sadness, anxiety or fear, and anger are all common features of experiences that are recalled and represented in memory and sometimes in identity, whether arising out of personal life experiences or as a result of political or social events. One reason that events get encoded in memory may be their anticipated consequentiality (Brown \& Kulik, 1977; Mackavey, Malley, \& Stewart, 1991), but researchers have shown that emotionally vivid experiences are recalled even when they are not consequential (Rubin \& Kozin, 1984). Based on the literature on autobiographical memory it is reasonable to expect that social-historical events that we experience are more likely to be encoded in our memories and even become part of our identities when they cause us to experience intense emotions, either at the time or in the aftermath, as when people feel guilt or shame about what happened (Dresler-Hawke \& Liu, 2006).

Personal and collective memory. We can distinguish between memory of events that took place in our personal lives, but had no larger social significance (or only affected a few close friends or family members), and memory of events that took place in the larger social arena-that in some sense did not precisely happen to us personally. While this is a tricky distinction (in order for us to recall events we must be aware of them, and they must have some personal meaning for us), it is nevertheless clear that many events that people recall in their lives arise well beyond their personal sphere. These include memories of war, of terrorism and assassination, and of disaster, whether the person was a participant in the 
events or a remote, but engaged "bystander" (Brown et al., 2009; Pennebaker \& Gonzalez, 2009; Pennebaker, Baez, \& Deschamps, 2006; Schuman \& Rodgers, 2004; Vollhardt \& Bilewicz, 2013; Wertsch \& Roediger, 2008). Of course in many cases people recall events that were both personal (their own actions during a war or disaster) and collective (World War II or Hurricane Katrina).

Identity and self-representations. Some memories become part of an individual's self-definition, or identity (Erikson, 1968). When this happens it may be as a result of a group identification (World War II veteran, Vietnam War protester, Holocaust survivor; see Tajfel, 1981), or identification with a generation or cohort of people who all experienced a particular historical event at the same age (Schuman \& Rieger, 1992; Schuman \& Rodgers, 2004; Stewart \& Healy, 1989). This may arise when a generation experiences traumatic events (e.g., the Great Depression; see Elder, 1974/1998), or when a generation is associated with particular social conditions at the time of its birth ("the baby boom") or its transition into adulthood (the 1960s generation). There is considerable evidence that when a generation comes of age during socially turbulent times, it is more likely to form group identification as a "cohort" or generation (Delli Carpini, 1989; Duncan \& Agronick, 1995; Mannheim, 1959; Stewart \& Healy, 1989), or as a member of a "subunit" of a generation (e.g., Civil Rights activists). Intergroup relations include relationships between people who identify with a particular social structure (gender, race/ethnicity or class; Apfelbaum, 1979; Gurin, Miller, \& Gurin, 1980) and those who may have experienced social-historical events in a particular way as a consequence of their place in the social structure (e.g., African Americans' vs. European Americans' experience of the assassination of Martin Luther King Jr., or women's vs. men's experience of the "second wave" women's movement; see Gausel, Leach, Vignole, \& Brown, 2012; Hilton \& Liu, 2008; Liu, Wilson, McClure, \& Higgins, 1999).

Social representations. When social-historical events are inscribed in personal identity, they are often articulated in a well-developed personal narrative-a life story that includes the place of that event in the story of the person's life (Stewart \& Healy, 1986). In the same way social-historical events may become the focus of collective narratives, or social representations of their meaning in history. These representations often include conflicts over the meaning of past events by members of different groups (Elcheroth, Doise, \& Reicher, 2011; Howarth, 2006; Wertsch \& Roediger, 2008), as in the case of debates by those who opposed or who fought in particular wars, or those with different views of territorial rights (as in the Middle East between Israelis and Palestinians). Liu and Hilton (2005) argue that historical narratives in fact help us define ourselves. They show that these narratives enable groups to define their relationship to other groups, providing them with explanations of the past that legitimize inequities in the present (see also Sibley \& Liu, 2011, for a detailed example). 
Social justice attitudes. Many social-historical events not only evoke group identifications, but often people view them in terms of their ideas about social justice. Thus, for example, Opotow $(2008,2011)$ has shown that the American Civil War and the Holocaust can both be understood as conflicts over moral inclusion - that is, who counts as part of the relevant moral universe. Equally, individuals who discount the claims of social groups on the "losing" side of historical events (e.g., racial ethnic minorities, like the Maori in New Zealand) use their understanding of history as having been "fair" to justify their endorsement of policies of continued exclusion (Sibley \& Liu, 2012). Other groups stake their support for reparations to certain groups on both their egalitarian attitudes about intergroup relations and their understanding of historical processes as having been "unfair" (Dresler-Hawke \& Liu, 2006; Nagata, 1993). Finally, individuals' views of a group's past history may increase or decrease their personal ambition or drive (Barreto, Ellemers, \& Palacio, 2004).

These five elements, though of course they do not exhaust the possibilities, play key roles in linking history and psychology through pathways in which history is both uniquely personal and individual and collective psychologies give meaning to history. We do not suggest that there is a single role that any one of these elements plays. For example, intense emotions may arise both at the time of events and also in the aftermath; social justice attitudes may predispose certain reactions and may also influence how reactions are expressed in action; personal and collective memories both may shape identities for some around historical events, and certain social identifications or representations may make it more likely that particular events will arouse emotion and attention. Each of the articles in this volume draws on some of these elements in examining a particular instance of the intersection of psychology and history.

\section{Organization of the Issue}

Historical events, particularly those that are disruptive, transformative, or for which deeply held understandings or cherished values are viewed to be at stake, are a critical lens through which "history" is understood (Mills, 1959; Pennebaker \& Gonzales, 2009). Cherished values encode our sense of morality, of what is right and just. All of the historical events we highlight include issues of power, group-based inequalities and/or injustice; thus processes of meaningmaking include efforts to reconcile past-and sometimes present-injustice. This issue is organized into three sections: Representing History: Human Rights and Social Justice; Collective Memory, History and Construction of Identities; and (In) justice and Histories of Resistance: Intersection of Attitudes, Emotion and the Body. These investigations also provide examples of diverse methodological approaches and research designs, which focus on the perspectives both 
of actors in historical events or social movements, and those who observed its unfolding.

\section{Representing History: Human Rights and Social Justice}

The first section, Representing History: Human Rights and Social Justice, includes three articles that raise broad questions about different ways that representations of history, particularly the history of struggles over human rights and for social justice, are implicated in human psychology. Susan Opotow examines museum practices in representing past injustices by analyzing The Museum of Memory and Human Rights (El Museo de la Memoria y los Derechos Humanos) in Santiago Chile. She argues that the museum illuminates Chilean museumgoers' own history, illustrating how the "scope of justice" narrowed during the Pinochet regime and then expanded during its aftermath. She demonstrates as well how museum practices can intervene in social representations of the past and in individuals' imaginative reconstructions of it. While this article focuses on the representation of history for a national (Chilean) public, Brinton Lykes and Rachel Hershberg show how histories of struggles for human rights are transnational, both because of the intervention of one country in the politics of another (the United States in Guatemala) and because individuals emigrate to another country, and fear or experience deportation from it. They show how histories of violence shape and influence individuals' accounts of their migrations and immigration, and cast long shadows in their lives. They argue that because U.S. detention and immigration policies currently do not acknowledge the residue of struggles for justice and citizenship that immigrants bring with them from their past environment, they reproduce and exacerbate family and individual strains. Finally, Andrea Hunter and Alethea Rollins examine how national (and international) experiences-like World War II-are indelibly and complexly represented in the identities of particular actors like the Tuskegee Airmen. In this account a group that shares a particular experience of injustice as African American men aims self-consciously to create a legacy that transcends that experience and defines them as a special group of American military patriots who were also effective "race men" who sought to make the larger case against Black inferiority and for equality of civil rights through excellence and achievement.

\section{Collective Memory, History and Construction of Identities}

The second section, Collective Memory, History and Construction of Identities, highlights the centrality of processes of memory and identity in making historical experiences psychologically meaningful. Roy Schwartzman shows how a collective trauma - such as that endured by Jewish Holocaust survivors-creates a demand for reconciliation of a pre-Holocaust Jewish identity and a post-Holocaust 
survivor identity. The process of constructing an identity that can incorporate, but not be defined by, the mass tragedy the individual has endured, can illuminate more general efforts individuals make simultaneously to represent the history they experience and to transcend it. Abigail Stewart, David Winter, Donna HendersonKing, and Eaaron Henderson-King examine how the history of the 1960s in the United States is differently recalled, and incorporated into identity, by Black and White men and women who lived through that period as young adults. They show that members of groups that felt directly implicated in the events recalled them very differently than did those - especially White men — who did not. They discuss the need for leaders who can successfully expand the scope of personal meaning of events so that meaning can be more widely shared, a suggestion that seems even more practical in light of the results of the next article. Nida Bikmen demonstrates that experimental invocation of a group's social history-particularly its history of accomplishment, implicitly suggesting that it is personally relevanthas immediate consequences for test performance for both African American and women students. Finally, Veronika Nourkova and Norman Brown examine a crucial historical event - the collapse of the Soviet Union-that is nevertheless unrepresented in the autobiographical memories of current occupants of the former Soviet Union who were young adults during that period. This lacuna in the personal meaning of an undoubtedly significant historical event provides an opportunity for consideration of the necessary conditions for events to become personally meaningful.

\section{(In) justice and Histories of Resistance: Intersection of Attitudes, Emotion and the Body}

Finally, in the last section the articles focus on (In) justice and Histories of Resistance: Intersection of Attitudes, Emotion and the Body. Four articles examine how historical conflicts are reflected in the attitudes, and emotional and physical responses, of people years later. In the first article, Ronni Greenwood examines how emotions are used by contemporary White residents of Tulsa Oklahoma in their debate about the 1921 race riot and whether descendants of victims should receive reparations. She shows that proponents of reparations rely on arguments based mainly on positive emotions (hope and gratitude, for example) and positive features of group identity (generosity, for example), showing how emotions and identities are not merely "results" of historical events, but are also instrumental tools for dealing with their aftermath. Donna Nagata, Jackie Kim, and Teresa Nguyen examine the different emotional and interpersonal responses of two generations of Japanese Americans: those who experienced internment directly during World War II, and those who were their children. They show that personal experiences of historical events live on-both represented and unrepresentedin subsequent generations' experience and behavior, taking one kind of politicized shape in the reparations movement. Phillip Hammack and Andrew Pilecki 
show that the precise way that groups talk about their deeply contentious histories (specifically Palestinians and Jews in Israel) matters for maintaining or challenging power relations in the present. They found that compared with a dialogue emphasizing coexistence, a confrontational dialogue offered a greater opportunity for generating a new power dynamic between groups with very different power at the outset. This study then offers a method for using dialogue about historical intergroup conflict as a tool for conflict resolution that also addresses current social inequality. Finally, Breanne Fahs examines pedagogy as a field of social representation in which second wave feminist efforts to empower individual women in relation to their bodies have largely dropped out of third wave teaching practices-practices which continue to focus on the body, but not on women's agency. She suggests ways that teaching approaches that integrate the insights of both second and third wave feminism could have greater impact.

\section{References}

Apfelbaum, E. (1979). Relations of domination and movements for liberation: An analysis of power between groups. In W. G. Austin, \& S. Worchel (Eds.), The social psychology of intergroup relations. Belmont, CA: Wadsworth.

Barreto, M., Ellemers, N., \& Palacios, M. S. (2004). The backlash of token mobility: The impact of past group experiences on individual ambition and effort. Personality and Social Psychology Bulletin, 30(11), 1433-1445.

Brown, N. R., Lee, P. J., Krslak, M., Conrad, F. G., Hansen, T. G. B., Havelka, J., \& Reddon, J. R. (2009). Living in history: How war, terrorism and national disaster affect the organization of autobiographical memory. Psychological Science, 20(4), 399-405.

Brown, R., \& Kulik, J. (1977). Flashbulb memories. Cognition, 5, 73-99.

Crane, S. (1997). Writing the individual back into collective memory. The American Historical Review, 12(5), 1372-1385.

Delli Carpini, M. X. (1989). Age and history: Generations and sociopolitical change. In R. Sigel (Ed.), Political learning in adulthood (pp. 11-55). Chicago, IL: University of Chicago Press.

Dresler-Hawke, E., \& Liu, J. H. (2006). Collective shame and the positioning of German national identity. Psicologia Politica, 32, 131-155.

Duncan, L. E., \& Agronick, G. S. (1995). The intersection of life stage and social events: Personality and life outcomes. Journal of Personality and Social Psychology, 69(3), 558-568. doi:10.1037/0022-3514.69.3.558.

Elcheroth, G., Doise, W., \& Reicher, S. (2011). On the knowledge of politics and the politics of knowledge: How a social representations approach helps us rethink the subject of political psychology. Political Psychology, 32(5), 729-758.

Elder, G. (1974/1998). Children of the great depression. $\left(25^{\text {th }}\right.$ anniversary edn.). Boulder, CO: Westview Press.

Erikson, E. (1968). Identity: Youth and crisis. NY: Norton.

Gausel, N., Leach, C. W., Vignole, V. L., \& Brown, R. (2012). Defend or repair? Explaining responses to ingroup moral failure by disentangling feelings of shame, rejection and inferiority. Journal of Personality and Social Psychology, 102(5), 941-960.

Gurin, P., Miller, A. H., \& Gurin, G. (1980). Stratum identification and group consciousness. Social Psychology Quarterly, 43, 30-47.

Gourevitch, P. (2014, April 14). Remembering in Rwanda. The New Yorker, 31-32.

Hilton, D. J., \& Liu, J. H. (2008). Culture and intergroup relations: The role of social representations of history. In R. Sorrentino \& S. Yamaguchi (Eds.), The handbook of motivation and cognition: The cultural context (pp. 343-368). NY: Guilford. 
Howarth, C. (2006). A social representation is not a quiet thing: Exploring the critical potential of social representations theory. British Journal of Social Psychology, 45, 65-86.

Leach, C. W., Bou Zeineddine, F., \& Čehajić-Clancy, S. (2013). Moral immemorial: The rarity of self-criticism for previous generations' genocide or mass violence. Journal of Social Issues, 69(1), 34-53.

Liu, J. H., \& Hilton, D. J. (2005). How the past weighs on the present: Social representations of history and their role in identity politics. British Journal of Social Psychology, 44, 537-556.

Liu, J. H., Wilson, M. W., McClure, J., \& Higgins, T. R. (1999). Social identity and the perception of history: Cultural representations of Aotearoa/New Zealand. European Journal of Social Psychology, 29, 1021-1047.

Mackavey, W. R., Malley, J. E., \& Stewart, A. J. (1991). Remembering autobiographically consequential experiences: Content analysis of psychologists' accounts of their lives. Psychology and Aging, 6(1), 50-59.

Mannheim, K. (1959). Essays on the sociology of knowledge. London: Routledge.

Mills, C. W. (1959). The sociological imagination. Chicago: University of Chicago Press.

Nagata, D. (1993). Legacy of injustice. NY: Plenum.

Opotow, S. (2008). "Not so much as place to lay our head... ": Moral inclusion and exclusion in the American Civil War Reconstruction. Social Justice Research, 21, 26-49.

Opotow, S. (2011). How this was possible: Interpreting the Holocaust. Journal of Social Issues, 67(1), 205-224.

Pennebaker, J. W., \& Gonzales, A. (2009). Making history; Social and psychological processes underlying collective memory. In P. Boyer, \& J.V. Wertsch (Eds.), Memory in mind and culture (pp. 171-193). NY: Cambridge University Press.

Pennebaker, J. W., Baez, D., \& Deschamps, J. C. (2006). The social psychology of history: Defining the most important events of the last 10, 100 and 1000 years. Psicologica Politica, 32, 15-32.

Pillemer, D. B. (1984). Flashbulb memories of the assassination attempt on President Reagan. Cognition, 16, 63-80.

Pillemer, D. B. (1998). Momentous events, vivid memories. Cambridge, MA: Harvard University Press.

Pillemer, D. B. (2001). Momentous events and the life story. Review of General Psychology, 5(2), 123-134.

Rubin, D. C. (Ed.)(1986). Autobiographical memory. Cambridge, England: Cambridge University Press.

Rubin, D. C., \& Kozin, M. (1984). Vivid memories. Cognition, 16, 81-95.

Schuman, H., \& Rieger, C. (1992). Historical analogies, generational effects, and attitudes toward war. American Sociological Review, 57, 315-326.

Schuman, H., \& Rodgers, W. L. (2004). Cohorts, chronology, and collective memories. Public Opinion Quarterly, 68(2), 217-254.

Sibley, C. G., \& Liu, J. H. (2011). Social representations of history and the legitimation of social inequality: The causes and consequences of historical negation. Journal of Applied Social Psychology, 42(3), 598-623.

Stewart, A. J., \& Healy, J. M., Jr. (1986). The role of personality development and experience in shaping political commitment: An illustrative case. Journal of Social Issues, 42(2), 11-32.

Stewart, A. J., \& Healy, J. M. (1989). Linking individual development and social changes. American Psychologist, 44, 30-42.

Tajfel, H. (1981). Human groups and social categories. NY: Cambridge University Press.

Vollhardt, J. R., \& Bilewicz, M. (2013). After the genocide: Psychological perspectives on victim, bystander, and perpetrator groups. Journal of Social Issues, 69(1), 1-15.

Wertsch, J. V., \& Roediger, H. L., III (2008). Collective memory: Conceptual foundations and theoretical approaches. Memory, 16(3), 318-326.

ANDREA G. HUNTER is an Associate Professor in the Department of Human Development and Family Studies and the Director of the School of Health and Human Sciences Office of Diversity and Inclusion at The University of North 
Carolina at Greensboro. Her research interests focus on African American families, and the influences of race, gender, social class, and culture on the life course, families, and well-being.

ABIGAIL J. STEWART is Sandra Schwartz Tangri Distinguished University Professor of Psychology and Women's Studies at the University of Michigan. Her current research examines educated women's lives and personalities; women's movement activism both in the United States and globally; gender, race and generation; and institutional change in the academy. 